\title{
Cyclic AMP-Sensitive Chloride Efflux in Rabbit Pancreatic Acini
}

\author{
H. KOPELMAN AND C. GAUTHIER \\ Division of Gastroenterology, Department of Pediatrics, Montreal Children's Hospital and the McGill University- \\ Montreal Children's Hospital Research Institute, Montreal, Canada
}

\begin{abstract}
We studied chloride efflux from isolated rabbit pancreatic acini in suspension, by loading with ${ }^{36} \mathrm{Cl}$ to steady state and rapidly washing acini by filtration to determine ${ }^{36} \mathrm{Cl} \mathrm{cpm} / \mu \mathrm{g}$ DNA remaining. Linear loss of acinar chloride occurred over $5 \mathrm{~min}(\mathrm{k}=\mathbf{0 . 0 3 8} \pm 0.008$ $\left.\min ^{-1}, n=5\right)$. Forskolin $\left(5 \times 10^{-5} \mathrm{M}\right)$ increased the rate of chloride efflux $\left(\mathrm{k}=0.100 \pm 0.016 \mathrm{~min}^{-1}, n=5, p<\right.$ 0.001 ) 2.6-fold. At $5 \mathrm{~min}$, forskolin increased acinar cAMP levels $(1065 \pm 254$ versus $7 \pm 2 \mathrm{pmol} / \mathrm{mL}, n=5, p<$ $0.005)$ and percentage of chloride efflux $(37.4 \pm 2.3$ versus $26.0 \pm 2.2 \%, n=13, p<0.005)$. The chloride channel inhibitor anthracene-9-carboxylic acid $\left(10^{-3} \mathrm{M}\right)$ had no effect on chloride loss from acini exposed to vehicle (30.9 \pm 1.9 versus $29.9 \pm 2.3 \%, n=4$ ), but completely inhibited forskolin-stimulated efflux at $5 \mathrm{~min}(40.0 \pm 2.4$ versus 29.3 $\pm 2.4 \%, n=5, p<0.005$ ). Manipulation of extracellular calcium concentration demonstrated that chloride efflux was not coupled to zymogen granule amylase release. Secretin $\left(10^{-7} \mathrm{M}\right)$ increased acinar cAMP levels $(68 \pm 22$ versus $7 \pm 2 \mathrm{pmol} / \mathrm{mL}, n=5, p<0.05$ ) and significantly increased the loss of chloride from acini $(34.9 \pm 1.4$ versus $26.1 \pm 1.7 \%, n=7, p<0.005$ ) without affecting amylase release. Secretagogue-stimulated amylase release by cholecystokinin octapeptide $\left(10^{-8} \mathrm{M}\right)$ and carbamylcholine $\left(10^{-5} \mathrm{M}\right)$, did not increase chloride efflux at $5 \mathrm{~min}$. Our findings demonstrate that pancreatic acini possess a chloride efflux pathway that is conductive, cAMP responsive, and distinct from zymogen granule membrane conductance. (Pediatr Res 29: 529-533, 1991)
\end{abstract}

\section{Abbreviations}

A9C, anthracene-9-carboxylic acid
CCK, cholecystokinin
CCK-OP, cholecystokinin octapeptide
carbachol, carbamylcholine
HEPES, $N$-2-hydroxyethylpiperazine- $N^{\prime}$-2-ethanesulfonic
acid
CF, cystic fibrosis

Advances in our understanding of the pathophysiologic disturbances occurring in CF have pointed to a basic defect in the apical transport of chloride by epithelial cells $(1,2)$. The consequences of this defect are thought to account for the clinical manifestations of this disease. According to current models, a regulated apical conductive chloride pathway is an important component of the membrane transport mechanisms necessary

Received September 6, 1990; accepted January 30, 1991.

Correspondence: H. Kopelman, 2300 Tupper D596, Montreal, H3H 1P3, Canada.

Supported by the Canadian Cystic Fibrosis Foundation and the Medical Research Council of Canada. H.K. is a Canadian Cystic Fibrosis Foundation Scholar. for fluid and chloride secretion by epithelial cells (3). To characterize chloride transport in pancreatic acinar epithelium, an apparent target of the CF genetic defect, we studied rates of chloride efflux from suspensions of isolated rabbit pancreatic acini loaded with radiolabeled ${ }^{36} \mathrm{Cl}$ under different experimental conditions. In these cells, we identified a conductive chloride efflux pathway, distinct from zymogen granule membrane conductance, activated by cAMP and the physiologic hormone secretin.

\section{MATERIALS AND METHODS}

Materials. Drugs and chemicals were obtained from the following sources: chromatographically purified collagenase (Type CLSPA) from Worthington Diagnostic Systems Inc., Freehold, $\mathrm{NJ}$; CCK-OP from Peninsula Laboratories, Inc., Belmont, CA; secretin, carbachol, forskolin, and soybean trypsin inhibitor from Sigma Chemical Co., St. Louis, MO; A9C from Aldrich, Milwaukee, WI; and ${ }^{36} \mathrm{Cl}$ and ${ }^{3} \mathrm{H}$-mannitol from ICN Biomedical, Irvine, CA. The Phadebas amylase kit was obtained from Pharmacia Fine Chemicals, Piscataway, NJ. All other reagents were of chemical grade and were obtained from commercial sources.

Preparation of pancreatic acini. Pancreatic acini were isolated using a technique modified from that described by Williams et al. (4). Male New Zealand White rabbits weighing $2-2.5 \mathrm{~kg}$ were killed by exposure to $\mathrm{CO}_{2}$ for 2-3 minutes. This protocol was approved by the McGill University Animal Care Committee. The pancreas was removed surgically, injected, and incubated successively three times with collagenase ( 45 units $/ \mathrm{mL}$ ), mechanically dispersed by pipette, filtered, and purified by centrifugation through $4 \%$ BSA. Acini from one rabbit were incubated for at least $10 \mathrm{~min}$ before study in 4-6 $\mathrm{mL}$ of a well-oxygenated HEPES

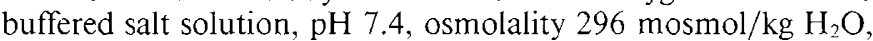
containing (in $\mathrm{mM}$ ): $115 \mathrm{NaCl}, 5.9 \mathrm{KCl}, 2.1 \mathrm{KH}_{2} \mathrm{PO}_{4}, 2.5 \mathrm{CaCl}_{2}$, $1.2 \mathrm{MgCl}_{2}, 11.5$ glucose, $0.3 \mathrm{~L}$-glutamine, 25 HEPES, $0.02 \%$ soybean trypsin inhibitor, and $1 \%$ BSA. Each acinar preparation was examined by light microscopy and viability assessed by trypan blue exclusion.

Chloride transport studies. Acinar transport studies were performed according to Melvin et al. (5) with modifications. Acini were incubated with ${ }^{36} \mathrm{Cl}(5.5 \mu \mathrm{Ci} / \mathrm{mL})$ at $37^{\circ} \mathrm{C}$. Uptake of ${ }^{36} \mathrm{Cl}$ achieved steady state maximal levels $(246 \pm 21 \mathrm{cpm} / \mu \mathrm{g}$ DNA, $n$ $=5$ ) by $20 \mathrm{~min}$ (Fig. 1). Acini were centrifuged for $1 \mathrm{~min}$ at 1000 $\mathrm{rpm}$ to remove ${ }^{36} \mathrm{Cl}$-containing medium and resuspended in chloride-free medium, pH 7.4, osmolality $296 \mathrm{mosmol} / \mathrm{kg} \mathrm{H}_{2} \mathrm{O}$, containing (in $\mathrm{mM}$ ): $150 \mathrm{Na}$ gluconate, $10 \mathrm{HEPES}$, and 10 mannitol. Calcium $(2.5 \mathrm{mM})$ was included in the medium of experiments with secretin, CCK, and carbachol. Two min after resuspension of acini in $\mathrm{Cl}$-free medium, an aliquot of acinar suspension ( $100 \mu \mathrm{L}$, containing approximately $10^{5}$ acini, 20-25 $\mu \mathrm{g}$ DNA) was removed from each sample for determination of basal $\mathrm{Cl}$ content. Samples were then exposed to test agents or the vehicle in which agents were dissolved. Aliquots of acinar suspension $(100 \mu \mathrm{L})$ removed before and at timed intervals after 
the addition of test agent or vehicle were washed on Millipore filters $(0.8 \mu \mathrm{m})$ three times with a total of $6 \mathrm{~mL}$ of ice cold $\mathrm{Cl}$ free medium. In initial experiments in which the extracellular marker ${ }^{3} \mathrm{H}$-mannitol was included, correction for extracellular chloride counts remaining on the filters after washing was $<0.001 \%$, and this practice was discontinued.

Filters were boiled in $1.5 \mathrm{~N}$ perchloric acid at $70^{\circ} \mathrm{C}$ for $15 \mathrm{~min}$ according to Melvin et al. (5) to extract DNA and Cl counts. Aliquots were then analyzed for DNA by modifications of the diphenylamine reaction $(6)$ and ${ }^{36} \mathrm{Cl}$ content was analyzed by liquid scintillation counting. Acinar chloride counts were corrected per $\mu \mathrm{g}$ DNA, rather than protein, because of secretagogueinduced alterations in acinar protein content. Data are expressed as $\% \mathrm{cpm} / \mu \mathrm{g}$ DNA remaining relative to basal values for each sample or as percentage of chloride efflux.

Assays. Amylase release from pancreatic acinar suspensions was measured by determining the amylase activity released into the extracellular medium during a timed interval and expressing this as a percentage of the total amylase activity, measured in cells and supernatant after a timed interval, according to Larose and Morisset (7). Data in response to secretagogues were normalized to amylase release during the same interval in the presence of vehicle. There was no systematic difference in vehicle amylase release in $2.5 \mathrm{mM}$ calcium versus $1 \mathrm{mM}$ EGTA. Amylase activity was measured by the Phadebas reaction.

Acinar cAMP content was determined by RIA, using acetylation of samples and standards to increase sensitivity. Antibody was produced according to the method of Brooker et al. (8). Dilutions of $10^{-3}$ provided $50 \%$ binding and no cross-reaction with cGMP, GTP, GDP, GMP, ATP, ADP, or AMP. Succinyl cAMP trimethyl ester was iodinated by the chloramine T method and separated from free iodine on Sep Pak columns. Aliquots of acinar suspension incubated in the presence of $0.5 \mathrm{mM} \mathrm{3-}$ isobutyl-1-methylxanthine were acidified with $\mathrm{HCl}$, sonicated, and centrifuged. The supernatant was stored at $-80^{\circ} \mathrm{C}$ until assay. Serial dilution of samples for linearity of response and cAMP recovery experiments confirmed the absence of significant interference in the assay.

Statistical analyses. All data are reported as mean \pm SEM of at least three experiments performed in duplicate except concen-

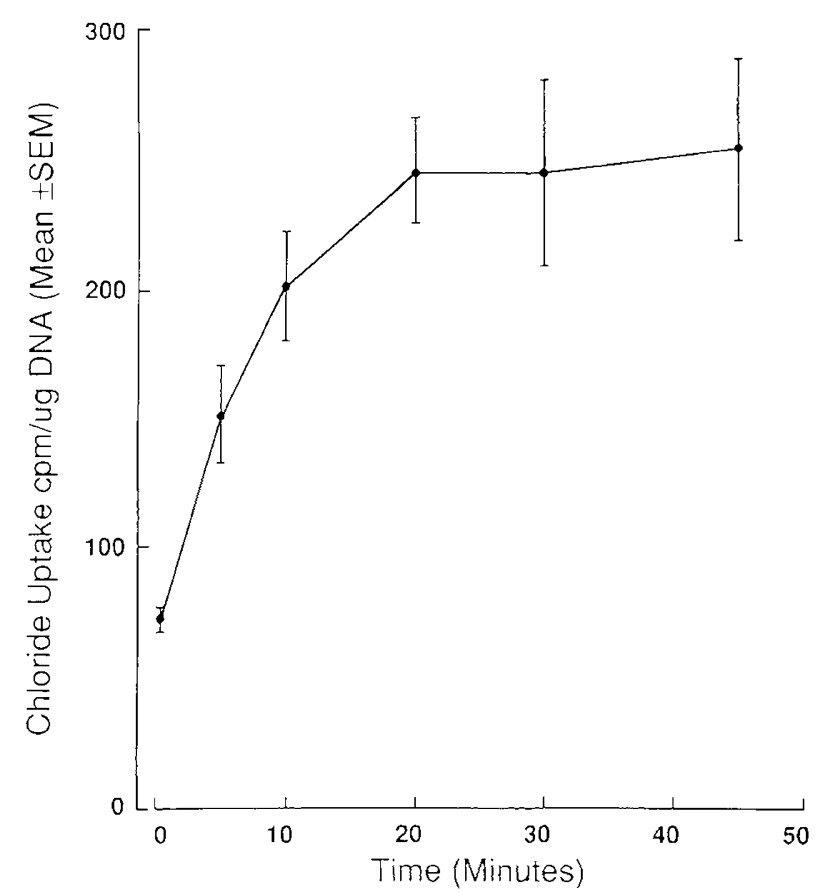

Fig. 1. Uptake of ${ }^{36} \mathrm{Cl}$ by isolated pancreatic acini in suspension. Steady state maximal levels were achieved by $20 \mathrm{~min}$ at $37^{\circ} \mathrm{C}$. Data shown are mean \pm SEM of five separate experiments in duplicate. tration-dependent amylase release in response to CCK-OP and carbachol, which were performed in triplicate. The number of samples assayed are denoted by $n$. Differences in means were determined using the unpaired two-tailed $t$ test for comparison of two experimental samples or conditions. Where multiple comparisons were tested, analysis of variance was also used.

\section{RESULTS}

Acinar preparation. Preparations of acini examined by phase contrast microscopy showed no evidence of contamination by ductal structures (Fig. 2). Viability of acini assessed by trypan blue exclusion was $>95 \%$ up to $4 \mathrm{~h}$ after isolation. There was no detectable increase in $\mathrm{LDH}$ activity in the medium during this time. Acini retained the ability to respond to CCK-OP and carbachol (Fig. 3) in a concentration-dependent fashion. Amylase release at $30 \mathrm{~min}$ as a percentage of total activity was halfmaximal at $10^{-10} \mathrm{M}$ and maximal at $10^{-8} \mathrm{M}$ CCK-OP, and was half-maximal at $5 \times 10^{-6} \mathrm{M}$ and maximal at $10^{-4} \mathrm{M}$ carbachol.

Effect of forskolin. Chloride efflux from preloaded acini is plotted on a semilogarithmic scale as the fraction of $\mathrm{cpm} / \mu \mathrm{g}$ DNA remaining in the cells over time (Fig. 4). The loss of chloride from acini was linear during the first $5 \mathrm{~min}$; the negative slope of the lines represents the apparent first order rate constant

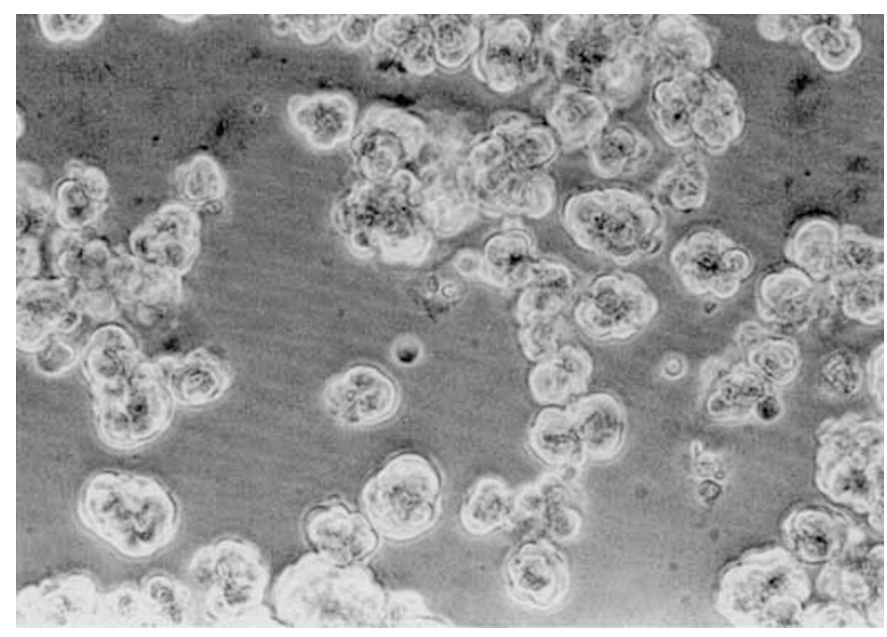

Fig. 2. Isolated rabbit pancreatic acini in suspension examined by phase contrast microscopy.
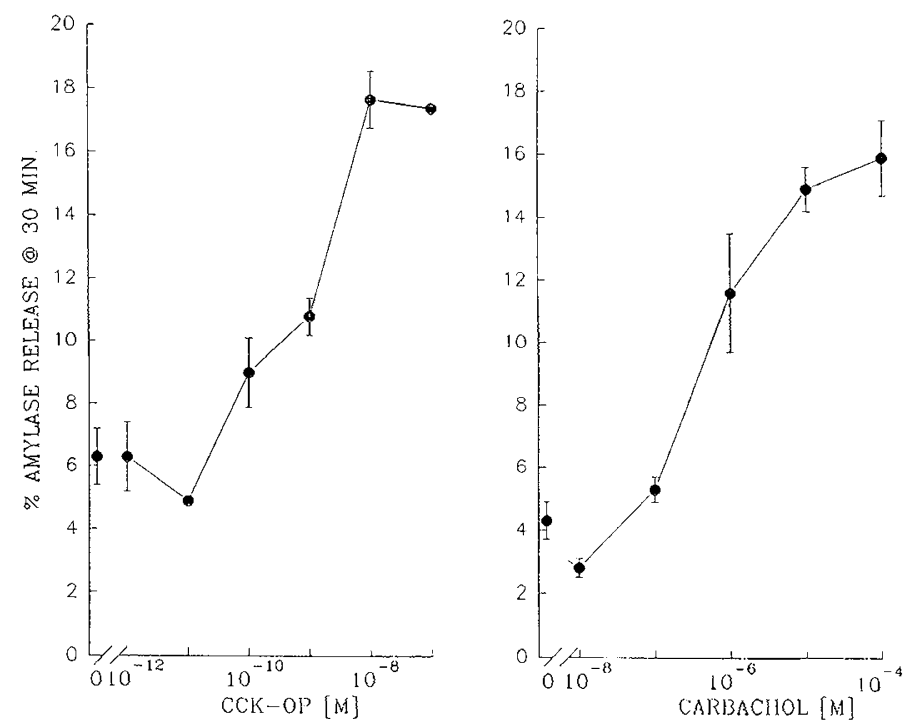

Fig. 3. Amylase secretory response to varying concentrations of CCK$\mathrm{OP}$ and carbachol at $30 \mathrm{~min}$ expressed as a percentage of total amylase activity. Data are mean \pm SEM of three to six experiments in triplicate. 


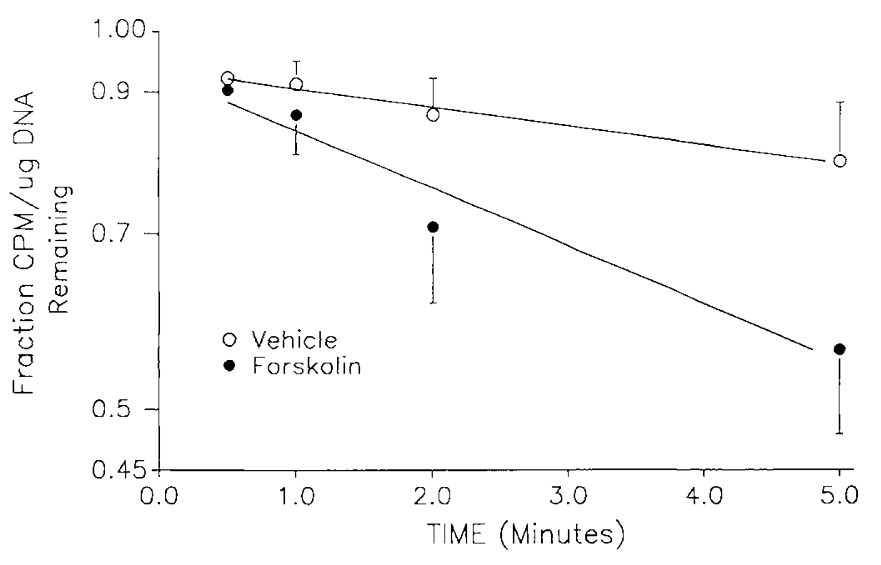

Fig. $4 .{ }^{36} \mathrm{Cl}$ efflux over time in rabbit pancreatic acini exposed to vehicle $(O)$ or forskolin $\left(-5 \times 10^{-5} \mathrm{M}\right.$ expressed as the fraction of $\mathrm{cpm} /$ $\mu \mathrm{g}$ DNA remaining. Data are mean \pm SEM of five separate experiments in duplicate, except for results at $0.5 \mathrm{~min}$, which are mean of two experiments in duplicate.

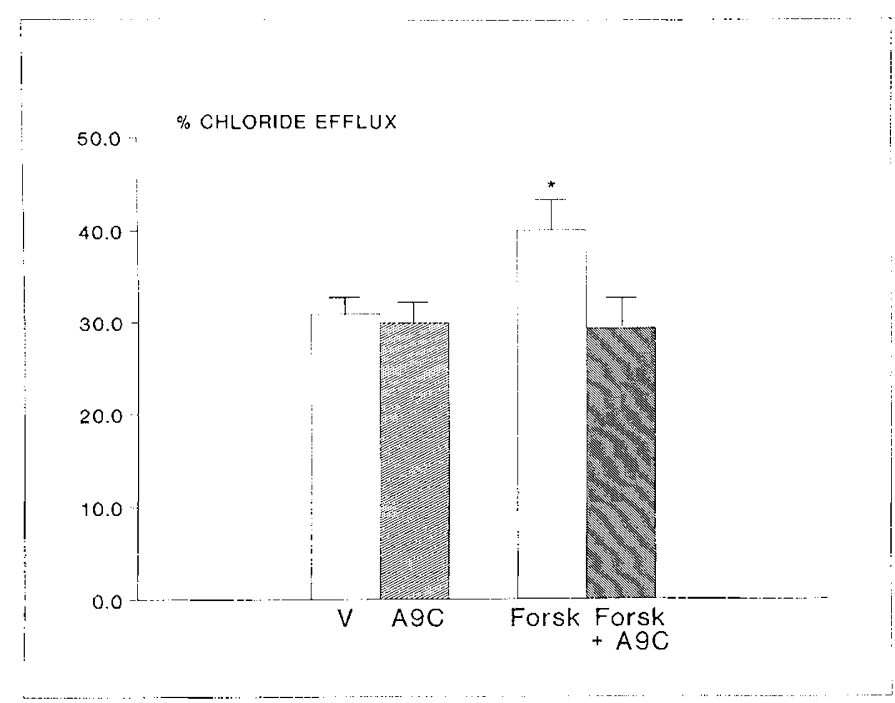

Fig. $5 .{ }^{36} \mathrm{Cl}$ efflux at $5 \mathrm{~min}$ in response to forskolin $5 \times 10^{-5} \mathrm{M}$ is completely inhibited in the presence of $\mathrm{A} 9 \mathrm{C} 10^{-3} \mathrm{M}(n=5)$. A9C had no effect on ${ }^{36} \mathrm{Cl}$ efflux in unstimulated acini $(n=4) .{ }^{*}, p<0.005, t$ test, forskolin vs forskolin $+\mathrm{A} 9 \mathrm{C}$.

$\left(\mathrm{k} \mathrm{m^{-1 }}\right)$ for chloride efflux. Forskolin $\left(5 \times 10^{-5} \mathrm{M}\right)$ increased the rate of efflux $\left(\mathrm{k}=0.100 \pm 0.016 \mathrm{~min}^{-1}, n=5, p<0.001\right)$ compared with cells exposed to vehicle alone $(0.038 \pm 0.008$ $\mathrm{min}^{-1}, n=5$ ). At $5 \mathrm{~min}$, forskolin significantly increased chloride efflux $(40.0 \pm 2.4 \%, n=5, p<0.001)$ compared with vehicle $(30.9 \pm 1.9 \%)$ and increased acinar cAMP levels $(1064.6 \pm 254$ $\mathrm{pmol} / \mathrm{mL}, n=5, p<0.005)$ compared with acini exposed to vehicle alone $(7.3 \pm 1.6, n=5)$. Subsequent data are reported for chloride efflux at 5 min.

To determine if chloride efflux involved a conductive pathway, we examined the effect of the chloride channel inhibitor, A9C, on basal and stimulated chloride efflux. Forskolin-stimulated chloride efflux at $5 \mathrm{~min}$ is shown in Figure 5 in the presence and absence of $\mathrm{A} 9 \mathrm{C}\left(10^{-3} \mathrm{M}\right)$. Forskolin-stimulated chloride efflux was completely inhibited by $\mathrm{A} 9 \mathrm{C}(40 \pm 2.4$ versus $29.3 \pm 2.4 \%$, $n=5, p<0.001)$. A9C had no effect on chloride efflux from acini exposed to vehicle alone $(30.9 \pm 1.9$ versus $29.9 \pm 2.3 \%)$.

To determine if chloride efflux was associated with zymogen granule release, we assessed chloride efflux in the presence of different extracellular calcium concentrations known to affect amylase secretion (Fig. 6). Addition of $2.5 \mathrm{mM}$ extracellular calcium to nominally calcium-free medium, necessary to support optimal amylase release, significantly inhibited forskolin-stimu-

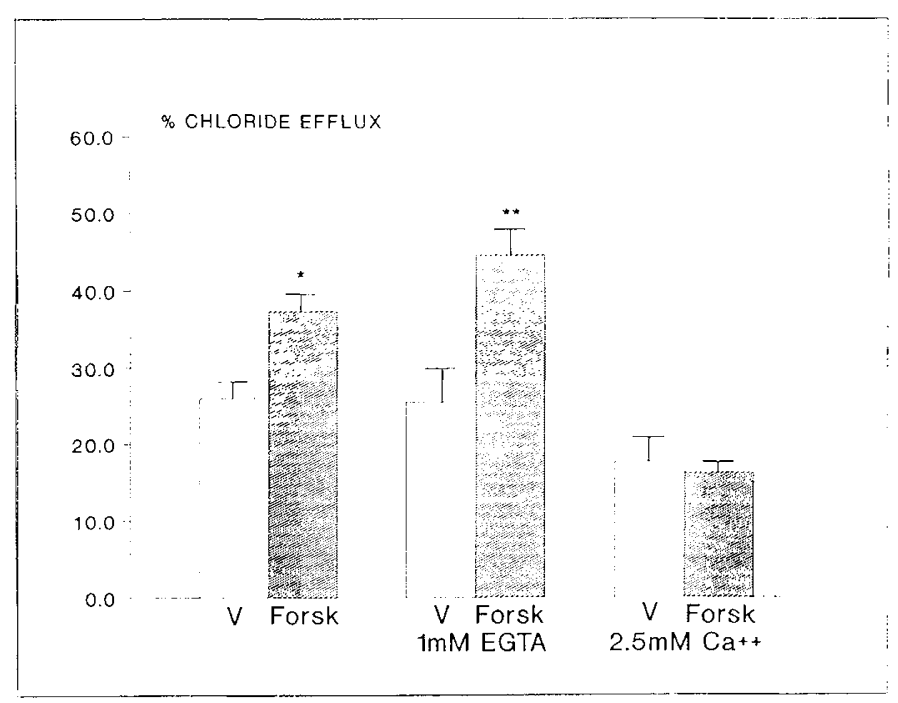

Fig. $6 .{ }^{36} \mathrm{Cl}$ efflux at $5 \mathrm{~min}$ in response to forskolin in the presence of no added extracellular calcium, $1 \mathrm{mM}$ EGTA, and $2.5 \mathrm{mM}$ added extracellular calcium. Control acini received vehicle under each of the above conditions of extracellular calcium. Multifactor analysis of variance and post hoc least significant difference identified significant effects of forskolin compared to vehicle in no-added-calcium medium $\left({ }^{*}, p<\right.$ $0.01)$ and in $1 \mathrm{mM}$ EGTA $(* *, p<0.001)$. The presence of $2.5 \mathrm{mM}$ calcium inhibited the effect of forskolin. Data are mean \pm SEM of seven experiments in duplicate except experiments in nominally calcium-free medium, where 13 experiments in duplicate are shown.

Table 1. Effect of secretagogues on amylase release at $5 \mathrm{~min} *$

\begin{tabular}{lcc}
\hline & \multicolumn{2}{c}{$\begin{array}{c}\text { Amylase release/vehicle amylase } \\
\text { release }\end{array}$} \\
\cline { 2 - 3 } & $1 \mathrm{mM}$ EGTA & $2.5 \mathrm{mM}$ Calcium \\
\hline Forskolin & $1.8 \pm 0.8(3)$ & $3.9 \pm 1.5(3)$ \\
Carbachol & $1.1 \pm 0.1(3)$ & $4.4 \pm 2.1(3)$ \\
CCK-OP & & $2.7 \pm 0.6(3)$ \\
Secretin & & $0.8 \pm 0.2(4)$ \\
\hline
\end{tabular}

* Values are mean \pm SEM of the number of separate experiments (shown in parentheses) in duplicate.

lated chloride efflux $(16.2 \pm 3.8 \%, n=7)$. The extracellular calcium chelator, EGTA, at a concentration sufficient to completely block carbachol-stimulated amylase release in our system ( $1 \mathrm{mM}$ ) only served to enhance forskolin-stimulated chloride efflux $(44.7 \pm 3.1 \%, n=7)$. In contrast to the effects on chloride efflux, amylase release in response to forskolin was markedly reduced in $1 \mathrm{mM}$ EGTA ( $1.8 \pm 0.8$ times vehicle amylase release) but was well supported ( $3.9 \pm 1.5$ times vehicle amylase release) in the presence of $2.5 \mathrm{mM}$ extracellular calcium (Table 1).

Effect of receptor-occupying secretagogues. The effect of receptor-occupying secretagogues in stimulating chloride efflux is shown in Figure 7 . Secretin $\left(10^{-7} \mathrm{M}\right)$ significantly stimulated chloride efflux $(34.9 \pm 1.4$ versus $26.1 \pm 1.7 \% \mathrm{cpm} / \mu \mathrm{g}$ DNA, $n=7, p<0.005)$. Neither CCK-OP $\left(10^{-8} \mathrm{M}\right)$ nor carbachol $\left(10^{-5} \mathrm{M}\right)$ increased chloride efflux. The effect of secretin was associated with a significant (10-fold) increase in acinar cAMP levels $(67.5 \pm 22$ versus $6.7 \pm 1.6 \mathrm{pmol} / \mathrm{mL}, n=5, p<0.05)$. The effects of these secretagogues on amylase release are examined in Table 1. After $5 \mathrm{~min}$, secretin had no effect on amylase release $(0.8 \pm 0.2$ times vehicle amylase release), while both CCK-OP $\left(10^{-8} \mathrm{M}\right)$ and carbachol $\left(10^{-5} \mathrm{M}\right)$ stimulated amylase release 2.7 - and 4.4-fold, respectively.

\section{DISCUSSION}

We have demonstrated a chloride efflux pathway in intact pancreatic acini that is stimulated by cAMP. Chloride efflux 


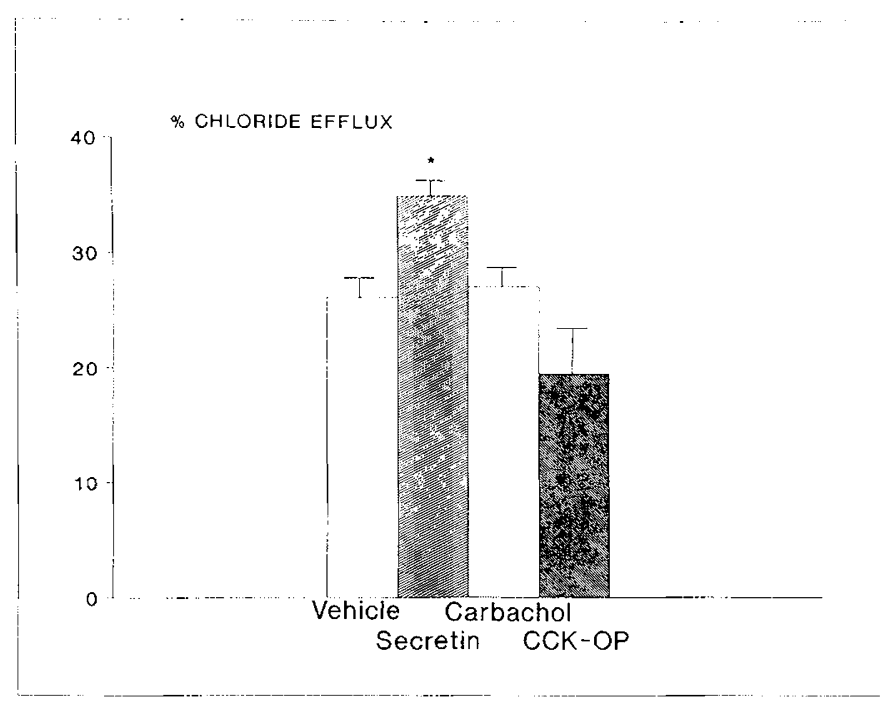

Fig. 7. Secretin $\left(10^{-7} \mathrm{M}\right)$ significantly increased ${ }^{36} \mathrm{Cl}$ efflux at $5 \mathrm{~min}$ compared to vehicle $\left(n=7 ;{ }^{*}, p<0.005 ; t\right.$ test $)$. Analysis of variance identified a significant treatment effect $(p<0.005)$. Post hoc least significant difference showed the effect of secretin to be significant at a value of $p<0.05$. Carbachol $\left(10^{-5} \mathrm{M}\right)$ had no effect on chloride efflux $(n=5)$. CCK-OP $\left(10^{-8} \mathrm{M}\right)$ decreased efflux $(n=6)$ but did not reach statistical significance.

from acini, maintained viable and functional in suspension, preloaded with ${ }^{36} \mathrm{Cl}$, and rapidly washed by filtration, could be measured and was linear for the first 5 min. This chloride efflux increased significantly in response to direct activation of the catalytic subunit of adenylyl cyclase by forskolin and in response to secretin, whose receptor is coupled to adenylyl cyclase. Both forskolin and secretin significantly increased cAMP content of pancreatic acini, supporting the existence of a cAMP-regulated chloride efflux in pancreatic acini.

An apical chloride conductance activated by cAMP (or hormones that raise cellular cAMP) has been associated with an increase in electrogenic chloride secretion in many epithelia (9). This chloride conductance in tracheal epithelium $(10,11)$ was sensitive to inhibition by $\mathrm{A} 9 \mathrm{C}$, an agent reported to inhibit chloride conductance across rabbit ascending loop of Henle (12) and rabbit gastric gland (13). A related anthracene derivative, $\mathrm{N}$ phenylanthranilic acid, inhibited chloride efflux in the chloridesecreting T84 colonic epithelial cell line (14). Our data, demonstrating that stimulated acinar chloride efflux could be completely inhibited by the chloride channel blocker A9C at similar concentrations, support the assumption that the chloride transport pathway is conductive. Although we cannot exclude cotransport or countertransport, we think these explanations for the observed chloride efflux are less likely for the following reasons: 1) We performed all experiments in this report in nominally $\mathrm{HCO}_{3}$-free conditions to minimize the contribution of $\mathrm{Cl} / \mathrm{HCO}_{3}$ exchange to any observed chloride efflux and 2) If observed efflux were due to cotransport, then CCK and carbachol, which increase cotransport in acini, should have increased the observed efflux. We saw no effect of these agents on chloride efflux; we have, therefore, interpreted our findings in favor of conductive chloride efflux. Confirmation of this assumption will require more specific chloride channel blockers, in the absence of positive electrophysiologic data.

The uncoupling of chloride loss and amylase secretion in our system demonstrated by the effects of extracellular calcium concentrations on forskolin-stimulated secretion and the effects of secretin, CCK, and carbachol strongly imply that the conductive chloride pathway that we have identified in acini is distinct from that described previously for zymogen granule membranes (1517). This pathway must be an integral part of the plasma membrane of cells contained within isolated acini and, presumably, it is localized to the apical membrane because, as yet, no basolateral chloride conductance has been identified in acinar cells (18).

Fluid secretion requires the loss of both $\mathrm{K}$ and $\mathrm{Cl}$ from epithelial cells. The important role of calcium-activated $\mathrm{K}$ channels in hormone-stimulated fluid secretion in salivary and pancreatic acini has been reviewed (19). Acetylcholine and CCK, by increasing intracellular calcium concentrations, in addition to activating protein kinase $\mathrm{C}$, increase the open-state probability of these $\mathrm{K}$ channels. Although activation of these basolateral $\mathrm{K}$ channels may increase $\mathrm{Cl}$ efflux because of membrane hyperpolarization, we saw no increase in chloride efflux in response to $\mathrm{CCK}$ or carbachol. $\mathrm{K}$ channel activation may also favor the uptake of $\mathrm{Cl}$ by $\mathrm{NaK}_{2} \mathrm{Cl}$ cotransport by increasing the electrochemical gradient favoring $\mathrm{K}$ uptake. This chloride uptake might completely compensate for any chloride efflux, accounting for our inability to demonstrate efflux in response to these agents. This explanation seems unlikely, however, since media chloride had been replaced by the impermeant anion gluconate, which should interfere with this uptake mechanism. Our inability to demonstrate pancreatic acinar chloride efflux in response to either CCK or carbachol, unlike parotid salivary acini (5), may account for the inability of CCK to stimulate pancreatic fluid secretion in some species (20).

It has recently been proposed that cAMP and calcium may activate separate chloride conductance pathways in chloride secreting epithelia (21). In airway epithelia, protein kinase $C$ inhibited chloride channel activation in the presence of high intracellular calcium concentrations (1). We speculate that the failure of CCK and carbachol to activate pancreatic acinar chloride efflux may be consistent with either the absence in pancreatic acini of a calcium-activated $\mathrm{Cl}$ channel or the presence of a chloride channel inhibitable by protein kinase $\mathrm{C}$ under conditions of increased intracellular calcium concentration.

The presence of a conductive chloride efflux responsive to secretin and adenylyl cyclase activation makes pancreatic acini an interesting model for the study of pancreatic chloride transport. Chloride channels in the epithelia of patients with CF do not respond to adenylate cyclase/protein kinase $\mathrm{A}$ activation $(22-26,1,2)$. Pancreatic fluid secretion is markedly diminished in CF patients (27), as is net pancreatic chloride output (28). The existence of a regulated conductive chloride pathway capable of supporting fluid secretion by pancreatic acini and its failure to respond to activation in $\mathrm{CF}$ patients may, in part, account for these observations.

Acknowledgment. The authors thank R. John MacLeod for his critical advice and encouragement.

\section{REFERENCES}

1. Welsh MJ 1990 Abnormal regulation of ion channels in cystic fibrosis epithelia FASEB J 4:2718-2725

2. Quinton PM 1990 Cystic fibrosis: a disease in electrolyte transport. FASEB J 4:2709-2717

3. Frizzell RA, Halm DR, Rechkemmer G, Shoemaker RL 1986 Chloride channel regulation in secretory epithelia. Fed Proc 45:2727-2731

4. Williams JA, Korc M, Dormer RL 1978 Action of secretagogues on a new preparation of functionally intact, isolated pancreatic acini. Am $J$ Physiol 235:E517-E524

5. Melvin JE, Kawaguchi M, Baum BJ, Turner RJ 1987 A muscarinic agoniststimulated chloride efflux pathway is associated with fluid secretion in rat parotid acinar cells. Biochem Biophys Res Commun 145:754-759

6. Richards GM 1974 Modifications of the diphenylamine reaction giving increased sensitivity and simplicity in the estimation of DNA. Anal Biochem 57:369-376

7. Larose $\mathrm{L}$, Morisset $\mathrm{J} 1985$ Cholinergic stimulation of pancreatic amylase release and muscarinic receptors: effect of ionophore A23187. Life Sci 37:255-261

8. Brooker G, Harper JF, Terasaki WL, Moylan RD 1979 Radioimmunoassay of cyclic AMP and cyclic GMP. Adv Cyclic Nucleotide Res 10:1-33

9. Liedtke CM 1989 Regulation of chloride transport in epithelia. Annu Rev Physiol 51:143-160

10. Welsh MJ 1984 Anthracene-9-carboxylic acid inhibits an apical membrane chloride conductance in canine tracheal epithelium. J Membr Biol 78:6171 
11. Shorofsky SR, Field M, Fozzard HA 1984 Mechanism of chloride secretion in canine trachea: changes in intracellular chloride activity with secretion. J Membr Biol 81:1-8

12. DiStephano A, Wittner M, Schlatter E, Lang HJ, Englert H, Greger R 1985 Diphenylamine-2-carboxylate, a blocker of the $\mathrm{Cl}$ conductive pathway in $\mathrm{Cl}$ transporting epithelia. Pflugers Arch 405:S95-S100

13. Cuppoletti J, Sachs $G 1984$ Regulation of gastric acid secretion via modulation of a chloride conductance. J Biol Chem 259:14952-14959

14. Mandel KG, Dharmsathaphorn K, McRoberts JA 1986 Characterization of a cAMP-activated $\mathrm{Cl}$ transport pathway in the apical membrane of a human colonic epithelial cell line. J Biol Chem 261:704-712

15. DeLisle RC, Hopfer U 1986 Electrolyte permeabilities of pancreatic zymogen granules: implications for pancreatic secretion. Am J Physiol 250:G489G496

16. Gasser KW, DiDomenico J, Hopfer U 1988 Secretagogues activate chloride transport pathways in pancreatic zymogen granules. Am J Physiol 254:G93G99

17. Fuller CM, Deetjen HH, Piiper A, Schulz 11989 Secretagogue and second messenger-activated $\mathrm{Cl}$ permeabilities in isolated pancreatic zymogen granules. Pflugers Arch 415:29-36

18. Petersen $\mathrm{OH}$, Gallacher DV 1988 Electrophysiology of pancreatic and salivary acinar cells. Annu Rev Physiol 50:65-80

19. Petersen $\mathrm{OH} 1986$ Calcium-activated potassium channels and fluid secretion by exocrine glands. Am J Physiol 251:G1-G13
20. Kopelman H, Thesee G, Gauthier C 1987 Secretin stimulates chloride secretion from the rabbit pancreas. Pediatr Pulmonol (suppl 1):114(abstr)

21. Cliff WH, Frizzell RA 1990 Separate $\mathrm{Cl}$ conductances activated by cAMP and $\mathrm{Ca}$ in Cl-secreting epithelial cells. Proc Natl Acad Sci USA 87:4956-4960

22. Sato K, Sato F 1984 Defective beta-adrenergic response of cystic fibrosis sweat glands in vivo and in vitro. J Clin Invest 73:1763-1771

23. Frizzell RA, Rechkemmer $G$, Shoemaker RL 1986 Altered regulation of airway epithclial cell chloride channels in cystic fibrosis. Science 233:558-560

24. Welsh MJ, Liedtke CM 1986 Chloride and potassium channels in cystic fibrosis airway epithelia. Nature 322:467-470

25. Schoumacher RA, Shoemaker R, Halm DR, Tallant EA, Wallace RW, Frizzell RA 1987 Phosphorylation fails to activate chloride channels from cystic fibrosis airway cells. Nature 330:752-754

26. Li M, McCann JD, Liedtke CM, Nairn AC, Greengard P, Welsh JM 1988 Cyclic AMP-dependent protein kinase opens chloride channels in normal but not cystic fibrosis airway epithelium. Nature 331:358-360

27. Kopelman H, Durie P, Gaskin K, Weizman Z, Forstner G 1985 Pancreatic fluid secretion and protein hyperconcentration in cystic fibrosis. $N$ Engl Med 312:329-334

28. Kopelman H Corey M, Gaskin K, Durie P, Weizman Z, Forstner G 1988 Impaired chloride secretion as well as bicarbonate secretion underlies the fluid secretory defect in the cystic fibrosis pancreas. Gastroenterology 95:349-355 